\title{
Relapsing necrotising sarcoid granulomatosis in a young patient
}

\section{To the Editors:}

The recent case of necrotising sarcoid granulomatosis described by ALIBERTI et al. [1] provides clinicians with an interesting insight into this rare condition. We would like to supplement the paucity of literature surrounding necrotising sarcoid granulomatosis and illustrate a case of our own. This was also in a young patient but did require treatment with oral corticosteroids at initial presentation and for a subsequent relapse.

A previously well 15-yr-old nonsmoking Caucasian female was referred to our chest clinic by her general practitioner with several months of pleuritic left-sided chest pain and fatigue. There was no past medical or family history of note, no relevant environmental exposures and the patient was receiving no regular medication. Clinical examination was unremarkable, and spirometry and laboratory parameters, including serum angiotensin-converting enzyme, were within normal limits. Chest radiography showed ill-defined consolidation at the left base and subsequent computed tomography showed multiple peripherally and pleurally based nodules throughout both lungs, but with no mediastinal lymphadenopathy. An openlung biopsy revealed large aggregates of non-necrotising granulomatous inflammation around the bronchioles and in the pleura. Granulomatous vasculitis was also evident, leading to luminal narrowing and in some cases occlusion. Stains for fungi and acid-alcohol-fast bacilli were negative. Taken together, the findings were consistent with the diagnosis of necrotising sarcoid granulomatosis. In view of the patient's continuing chest pain and fatigue, oral prednisolone $\left(30 \mathrm{mg} \cdot \mathrm{day}^{-1}\right)$ was started, and subsequently tapered and discontinued over the next 6 months with complete resolution of symptoms and chest radiograph changes. However, 3 months later, the patient developed further persistent chest pain with recurrence of illdefined consolidation on chest radiography associated with a fall of $1 \mathrm{~L}$ in vital capacity. A further oral corticosteroid course was commenced, which was slowly tapered and discontinued over the next 17 months. At that point, the chest radiograph was normal and the patient asymptomatic. The patient remained well and was discharged from regular follow-up 1 yr later.

Our case complements the few documented cases of necrotising sarcoid granulomatosis occurring in young patients with pulmonary involvement alone [1-3]. Moreover, unlike the cases previously described [1-3], our patient did require oral corticosteroids at initial presentation and for a subsequent relapse. This provides further evidence that the condition is steroid-responsive and gives clinicians reason to be relatively optimistic when treatment is required in young symptomatic individuals.

\section{G.P. Currie*, K.M. Kerr ${ }^{\#}$ and J.S. Legge*}

Depts of *Respiratory Medicine, and "Pathology, Aberdeen Royal Infirmary, Aberdeen, UK.

\section{STATEMENT OF INTEREST}

None declared.

\section{REFERENCES}

1 Aliberti S, Falleni M, Tarsia P, et al. A 13-year-old female with shortness of breath and pleuritic chest pain. Eur Respir J 2006; 28: 876-882.

2 Heinrich D, Gordjani N, Trusen A, Marx A, Hebestreit H. Necrotizing sarcoid granulomatosis: a rarity in childhood. Pediatr Pulmonol 2003; 35: 407-411.

3 Tauber E, Wojnarowski C, Horcher E, Dekan G, Frischer T. Necrotizing sarcoid granulomatosis in a 14-yr-old female. Eur Respir J 1999; 13: 703-705.

\section{Angiotensin-converting enzyme genotype and C-reactive protein in patients with COPD}

To the Editors:

In a recent issue of the European Respiratory Journal, MEYSMAN [1] suggested that in studies on the effects of angiotensinconverting enzyme (ACE) blockers in patients with chronic obstructive pulmonary disease (COPD), stratification for ACE gene polymorphism could potentially affect the outcomes under investigation. We have shown previously that the insertion (I)/ deletion (D) polymorphism at intron 16 of the ACE gene is linked to pulmonary artery pressure $(P \mathrm{pa})$ in patients with 
COPD [2]. In addition, in our recent study, increases in $P$ pa were associated with higher serum levels of high-sensitivity C-reactive protein (hsCRP), raising the possibility of a pathogenetic role of low-grade systemic inflammation in the pathogenesis of pulmonary hypertension secondary to COPD [3]. Since activation of the renin-angiotensin system is likely to contribute to inflammatory processes [4], we performed a post hoc analysis on the potential relationship between the I/D ACE gene polymorphism and circulating hsCRP levels in 72 patients with clinically stable COPD (56 male, mean \pm SD age $65.1 \pm 10.5 \mathrm{yrs,}$ forced expiratory volume in one second (FEV1) $45.8 \pm 17.4 \%$ predicted, arterial oxygen tension $\left.\left(\mathrm{Pa}_{2} \mathrm{O}_{2}\right) 8.2 \pm 1.8 \mathrm{kPa}\right)$ who were participants in our previous studies $[2,3]$. The I/D ACE polymorphism was determined as previously described [2]. Serum hsCRP levels were assessed in samples of peripheral venous blood drawn from the antecubital vein by chemiluminescent immunoassay (Randox, Crumlin, UK).

Serum hsCRP differed significantly between the II, ID, and DD groups (median (25th-75th percentile): 1.4 (0.9-2.7) versus 2.7 (1.5-6.1) versus $3.8(1.8-10.4) \mathrm{mg} \cdot \mathrm{L}^{-1}$, respectively; ANOVA on ranks, $\mathrm{p}<0.05)$. Moreover, the I/D ACE polymorphism predicted serum log hsCRP levels $(\mathrm{p}<0.05)$ independently of age, sex, FEV1 or $\mathrm{Pa}_{2} \mathrm{O}_{2}$.

In vitro studies on human vascular smooth muscle cells indicate that angiotensin II mediates a variety of proinflammatory effects through pleiotropic activation of nuclear factor- $\mathrm{\kappa} B$ transcription factors [4]. Importantly, angiotensin II receptor blockade significantly reduced serum hsCRP and tumour necrosis factor- $\alpha$ in patients with systemic hypertension [5], suggesting that the renin-angiotensin system, and probably its genetic determinants, plays an important role in vascular microinflammation. On one hand, it is well known that carriers of the D allelle of the I/D ACE gene polymorphism have higher serum and tissue ACE activities [6]. On the other hand, however, the potential relationships between the ACE genotype and inflammatory cytokines have not been analysed previously in COPD patients. Our pilot study revealed a significant relationship between the I/D ACE gene polymorphism and circulatory CRP levels in patients with stable COPD: serum hsCRP increased from the homozygous II to the heterozygous ID and then to the homozygous DD ACE genotype group, and the I/D ACE gene polymorphism predicted serum $\log$ hsCRP levels independently of age, sex, FEV1 or $\mathrm{Pa}_{\mathrm{a}} \mathrm{O}_{2}$. This finding might be meaningful, particularly in the light of recently published data indicating the clinical importance and predictive value of CRP in patients with COPD [7, 8]. High CRP levels correlate with poorer performance in the 6-min walk test [7] and, in addition, they relate to increased mortality [8].

Animal studies are needed to shed more light on the mechanisms related to the induction and/or potentiation of inflammatory processes by the renin-angiotensin system. Moreover, future clinical studies are necessary to assess the potential relationships between the genetic determinants of the renin-angiotensin system and systemic complications in chronic obstructive pulmonary disease.

\section{R. Tkacova and P. Joppa}

Dept of Respiratory Medicine, Faculty of Medicine and L. Pasteur Teaching Hospital, P.J. Safarik University, Kosice, Slovakia.

\section{SUPPORT STATEMENT}

This study was supported by operating grants VEGA 1/2305/ 05 of the Ministry of Education and 2005/5-FNLPKE-01 of the Ministry of Health, Slovakia.

\section{STATEMENT OF INTEREST}

None declared.

\section{REFERENCES}

1 Meysman M. Angiotensin II blockers in obstructive pulmonary disease: a randomised controlled trial. Eur Respir J 2006; 28: 670-671.

2 Tkacova R, Joppa P, Stancak B, Salagovic J, Misikova S, Kalina I. The link between angiotensin-converting enzyme genotype and pulmonary artery pressure in patients with COPD. Wien Klin Wochenschr 2005; 117: 210-214.

3 Joppa P, Petrasova D, Stancak B, Tkacova R. Systemic inflammation in patients with COPD and pulmonary hypertension. Chest 2006; 13: 326-333.

4 Kranzhofer R, Schmidt J, Pfeiffer CAH, Hagl S, Libby P, Kubler W. Angiotensin induces inflammatory activation of human vascular smooth muscle cells. Arterioscler Thromb Vasc Biol 1999; 19: 1623-1629.

5 Fliser D, Buchholz K, Haller H. Antiinflammatory effects of angiotensin II subtype 1 receptor blockade in hypertensive patients with microinflammation. Circulation 2004; 110: 1103-1107.

6 Danser AH, Schalekamp MA, Bax WA, et al. Angiotensinconverting enzyme in the human heart. Effect of deletion/ insertion polymorphism. Circulation 1995; 15: 1387-1388.

7 de Torres JP, Cordoba-Lanus E, López-Aguilar C, et al. Creactive protein levels and clinically important predictive outcomes in stable COPD patients. Eur Respir J 2006; 27: 902-907.

8 Man SF, Connett JE, Anthonisen NR, Wise RA, Taskhin DP, Sin DD. C-reactive protein and mortality in mild to moderate obstructive pulmonary disease. Thorax 2006; 61: 849-853.

DOI: $10.1183 / 09031936.00147506$

\section{Diffuse panbronchiolitis: East meets West}

\section{To the Editors:}

In the paper by POLETTI et al. [1] on diffuse panbronchiolitis, the authors describe the diagnostic criteria for this condition and emphasise its predominance in East Asia, having associations with human leukocyte antigen (HLA)-Bw54 and HLA-A11.

We would like to highlight the difficulties and pitfalls in reaching this rare diagnosis in a European cohort of patients by 